\title{
Mid-term results of pelvic organ prolapse repair using a transvaginal mesh: the experience in Sherbooke, Quebec
}

\author{
Louis-Olivier Gagnon, MD; Le-Mai Tu, MD MSc FRCSC
}

\begin{abstract}
Objective: The objective was to report our experience on the implantation of the Prolift system since 2005.

Methods: Fifty-six patients were operated on between July 2005 and August 2008 by 1 surgeon. The patients were implanted with the transvaginal mesh, the Prolift system, for the treatment of recurrent or high-grade (Baden-Walker stage III or IV) multiple compartment pelvic organ prolapse (POP) associated with symptoms. A concomitant anti-incontinence surgery was performed in 38 patients (68\%).

Results: The population had a mean age of 68 (range 46-88), a body mass index of 27 (range 21-40) and a parity average of 3 (range 1-16). Previous POP repair had been performed in 17 patients $(30 \%)$ and a hysterectomy in $43(77 \%)$. The operating room time was on average 98 minutes (range 70-135), blood loss $81 \mathrm{~mL}$ (range 50-300) and hospital stay 3 days (range 1-10). With a median follow-up of 21 months, we found that the cure rate for POP was $91 \%(48 / 53)$ and the reoperation rate was $8 \%$ (4/53). Perioperative complications included 1 rectal laceration and 1 prolonged bleeding. Short-term postoperative complications included 10 episodes of transient urinary retention that required immediate tape release in 4 patients. Long-term complications included 5 POP recurrences, 2 low grade and 3 high grade.

Conclusion: The Prolift system appears to be a relatively safe and effective alternative to conventional surgeries for the treatment of recurrent or high-grade multiple compartment $\mathrm{POP}$, because of a high mid-term cure rate and a satisfactory complication profile. However, long-term follow-up is still needed to confirm these results.
\end{abstract}

\section{Résumé}

Objectif : Notre objectif ici est de parler de notre expérience avec I'implantation du système Prolift depuis 2005.

Méthodologie : Entre juillet 2005 et août 2008, 56 patientes ont été opérées par le même chirurgien. Les patientes ont subi une implantation du système de bandelette transvaginale Prolift, pour le traitement d'un prolapsus pelvien pluricompartimental récurrent ou de grade élevé (stade III ou IV de Baden-Walker) associé à des symptômes. Une chirurgie anti-incontinence concomitante a été réalisée chez 38 patientes (68\%).

Résultats : L'âge moyen de la population de l'étude était de 68 ans (entre 46 et 88 ans), l'indice de masse corporelle moyen était de 27 (entre 21 et 40), et en moyenne, la parité était de 3 (entre 1 et 16). Une intervention antérieure de correction d'un prolapsus pelvien avait été effectuée chez 17 patientes (30\%), et une hystérectomie, chez 43 patientes ( $77 \%$ ). En moyenne, la durée de l'intervention était de 98 minutes (de 70 à 135), la perte sanguine, de $81 \mathrm{~mL}$ (de 50 à 300) et la durée du séjour à l'hôpital, de 3 jours (de 1 à 10). Après un suivi médian de 21 mois, le taux de guérison observé pour le prolapsus pelvien était de $91 \%$ (48/53) et le taux de répétition de l'opération était de $8 \%$ (4/53). (Trois patientes perdues au suivi ne sont pas incluses dans le taux de guérison.) Les complications périopératoires incluent une lacération rectale et un épisode de saignement prolongé. Les complications postopératoires à court terme incluent 10 épisodes de rétention urinaire transitoire nécessitant un retrait immédiat de la bandelette chez 4 patientes. Les complications à long terme incluent 5 récidives du prolapsus pelvien, 2 de faible grade et 3 de grade élevé.

Conclusion : Le système Prolift semble être une solution de rechange relativement sûre et efficace aux interventions traditionnelles pour le traitement du prolapsus pelvien pluricompartimental récurrent ou de grade élevé, en raison d'un taux élevé de guérison à moyen terme et d'un profil de complications acceptable. Cependant, un suivi à long terme est toujours requis pour valider ces résultats.

Can Urol Assoc J 2010;4(3):188-91

\section{Introduction}

Pelvic organ prolapse (POP) is a common problem in the aging female. Treatment options for symptomatic POP include observation, pessary use and surgery. Conventional treatment strategies for $\mathrm{POP}$ repair have a recurrence rate of $20 \%$ to $30 \% .^{1-3}$ A new surgical technique of pelvic reconstruction using a transvaginal mesh, the Prolift system (Gynecare, Johnson and Johnson, Somerville, NJ), attempts to improve these results by providing mechanical support to the weakened pelvic floor.

With regard to the implantation of the Prolift system, a transvaginal approach is used with percutaneous insertion of implant straps. For the anterior compartment repair, 2 implant straps on each side are placed via the obturator foramen in the arcus tendinus fasciae pelvis. For the posterior compartment repair, 1 implant strap on each side is placed via the sacrospinous ligament.

The objective of this retrospective study was to report our experience on the implantation of the Prolift system since 2005. 
Pelvic organ prolapse repair

\begin{tabular}{ll}
\hline Table 1. Characteristics of the patients \\
\hline Characteristics & Patients \\
\hline No. patients & 56 \\
\hline Age, yr (range) & $68.1(46-88)$ \\
\hline BMI (range) & $27(21-40)$ \\
\hline Parity, no. (range) & $3,3(1-16)$ \\
\hline Menopausal status, no. (\%) & $53(95 \%)$ \\
\hline HRT, no. (\%) & $15(27 \%)$ \\
\hline $\begin{array}{l}\text { Preoperative UI, no. (\%) } \\
\text { - SUI } \\
\text { - Unmasked SUI }\end{array}$ & $30(54 \%)$ \\
\hline $\begin{array}{l}\text { Prior vaginal surgery, no. (\%) } \\
\text { - Anti-incontinence surgery } \\
\text { - Pelvic prolapse repair } \\
\text { - Hysterectomy }\end{array}$ & $8(14 \%)$ \\
\hline $\begin{array}{l}\text { BMI = body mass index; HRT = hormone replacement therapy; UI = urinary incontinence; } \\
\text { sUI = stress urinary incontinence. }\end{array}$ & $6(11 \%)$ \\
\hline
\end{tabular}

\section{Methods}

The population of the study included 56 patients who were operated on between July 29, 2005 and August 29, 2008, by 1 surgeon (LMT). Formal review and approval by the ethics committee of our institution was obtained.

Preoperative evaluation included a history, a cystoscopy with a detailed gynecological examination comprising a cough stress test, with full bladder and prolapse reduced, as well as a urodynamics study, with and without pessary and a quality-of-life questionnaire. All the patients were implanted with the transvaginal mesh (TVM), the Prolift system, for the treatment of recurrent or high-grade (BadenWalker stage III or IV) multiple compartment POP associated with symptoms. The technique used is in accordance with the technique described by the TVM group, led by Dr. Philipe Debodinance, in 2004. ${ }^{4}$ A concomitant antiincontinence surgery was performed in 38 patients $(68 \%)$. The transobturator vaginal tape was implanted in 34 patients, Aris (Coloplast, Minneapolis, MS) in 3 and TVT-SECUR (Gynecare, Johnson and Johnson, Somerville, NJ), in 1 for clinical stress urinary incontinence (SUI) or unmasked SUI, either with a cough stress test with prolapse reduced or a urodynamics study with pessary.

Follow-up after surgery was done at 2 months, 6 months, 12 months and then yearly for 3 years, with a history and physical exam, including a gynecological examinations. The cure rate was evaluated based on the results of these visits. The patients who were lost in follow-up were contacted via telephone. All the patients we contacted said they were cured (27/27). Only 3 patients were not included in the cure rate calculation: 2 could not be contacted via telephone, and 1 had the mesh removed during the surgery. Cure rate was defined as the functional cure of the POP.

\begin{tabular}{lcc}
\hline Table 2. Pelvic organ prolapse characteristics & \\
\hline Prolapse & No. $(\%)$ & $\begin{array}{c}\text { No. of stages } \\
\text { 3 and 4 (\%) }\end{array}$ \\
\hline Cystocele & $11(19.6 \%)$ & \\
- Stage 0-1 & $5(8.9 \%)$ & $40(71.4 \%)$ \\
- Stage 2 & $29(51.8 \%)$ & \\
- Stage 3 & $11(19.6 \%)$ & \\
- Stage 4 & & \\
\hline Uterine prolapse/colpocele & $12(21.4 \%)$ & \\
- Stage 0-1 & $19(33.9 \%)$ & $25(44.6 \%)$ \\
- Stage 2 & $11(19.6 \%)$ & \\
- Stage 3 & $14(25 \%)$ & \\
- Stage 4 & & \\
\hline Enterocele & $33(58.7 \%)$ & N/A \\
- Absent & & \\
- Present & $23(41.3 \%)$ & \\
& & \\
\hline Rectocele & & \\
- Stage 0-1 & & \\
- Stage 2 & & \\
- Stage 3 & $11(19.6 \%)$ & \\
- Stage 4 & $18(32.1 \%)$ & $278.2 \%)$ \\
\hline
\end{tabular}

\section{Results}

The population of the study had a mean age of 68 (range 46-88), a body mass index of 27 (range 21-40), a parity average of 3 (range 1-16) (Table 1). Previous POP repair had been performed in 17 patients $(30 \%)$ and a hysterectomy in $43(77 \%)$. High-grade genital prolapse was present in the anterior vaginal wall in $71 \%(40 / 56)$, apical wall in $45 \%(25 / 56)$ and posterior wall in $48 \%(27 / 56)$ (Table 2). Regarding operative data, a total mesh was used in 44 cases $(79 \%)$, an anterior mesh alone in $5(9 \%)$ and a posterior mesh alone in 7 (13\%) (Table 3). General anesthesia was used in 31 patients (55\%) and spinal anesthesia in 25 (45\%). The operating room time was on average $98 \mathrm{~min}$ utes (range 70-135), blood loss $81 \mathrm{~mL}$ (range 50-300) and hospital stay 3 days (range 1-10). With a median followup of 21 months, we found that the cure rate for POP was $91 \%(48 / 53)$ and the reoperation rate was 8\% (4/53) (Fig. 1). Perioperative complications included 1 anterior rectal wall laceration, that required primary repair and removal of the entire mesh, as well as 1 prolonged bleeding, which required embolization of the left internal iliac artery (Table 4). Short-term postoperative complications comprised 10 episodes of transient urinary retention that required immediate tape release in 4 patients, 2 cases of postoperative pain that lasted a maximum of 2 weeks and 1 episode of transient fever. Long-term complications included 5 organ prolapse recurrences, 2 low-grade POP, as well as 3 highgrade POP. One of the 2 low-grade recurrences required reoperation. The high-grade recurrences included 1 low rectocele grade III treated with another mesh, the Avaulta Plus (Bard Medical, Covington, GA), 1 colpocele grade III treated with an abdominal colposacropexy as well as 1 


\begin{tabular}{ll} 
Table 3. Operative characteristics & \\
\hline Technique used, no. (\%) & \\
- Total & $44(79 \%)$ \\
- Anterior alone & $5(9 \%)$ \\
- Posterior alone & $7(13 \%)$ \\
\hline Associated anti-incontinence surgery, no. (\%) & $38(68 \%)$ \\
\hline Operating room time, minutes (range) & $98(70-135)$ \\
\hline Blood loss, mL (range) & $81(50-300)$ \\
\hline Type of anesthesia, no. (\%) & \\
- General & $31(55 \%)$ \\
- Spinal & $25(45 \%)$ \\
\hline Hospital stay, days (range) & $2.9(1-10)$ \\
\end{tabular}

very low rectocele grade IV also treated with the Avaulta Plus. Also, long-term complications included 3 cases of de novo urinary incontinence. No case of vaginal erosion occurred in our series.

\section{Discussion}

In this study, the Prolift system demonstrated a high midterm cure rate, with a cure rate of $91 \%$ and only 5 POP recurrences. The 4 cases of POP recurrence that needed reoperation included one rectocele grade II and 1 low rectocele grade III that occurred following an anterior mesh implant only. The colpocele grade III occurred after a separated total mesh implant, because it was impossible during the initial surgery to develop a bridge at the vaginal cuff for the mesh to pass. The case of the very low rectocele grade IV following a total mesh implant may be explained by the fact that the Prolift system does not seem to provide good support of the posterior wall's lowest portion. In fact, the mesh does not cover the lowest $2 \mathrm{~cm}$ of the posterior wall. In that regard, the mesh Avaulta Plus gave better results.

Furthermore, the Prolift system had few major perioperative complications as well as few postoperative complications. In the perioperative period, only 1 prolonged bleeding and 1 rectal laceration occurred. In the postoperative period, no case of vaginal erosion was experienced because of the routine use of premarin cream before and after the surgery, which has now become the standard for most surgeons. The main concern was the 10 cases of transient urinary retention. However, only 4 of them required immediate tape release, the 6 others resolved naturally. The high rate of urinary retention coincided with a change in the time of the catheter removal from postoperative day 1 to postoperative day 2 . Since we reverted to removing the catheter on postoperative day 1 , the rate of urinary retention has decreased significantly.

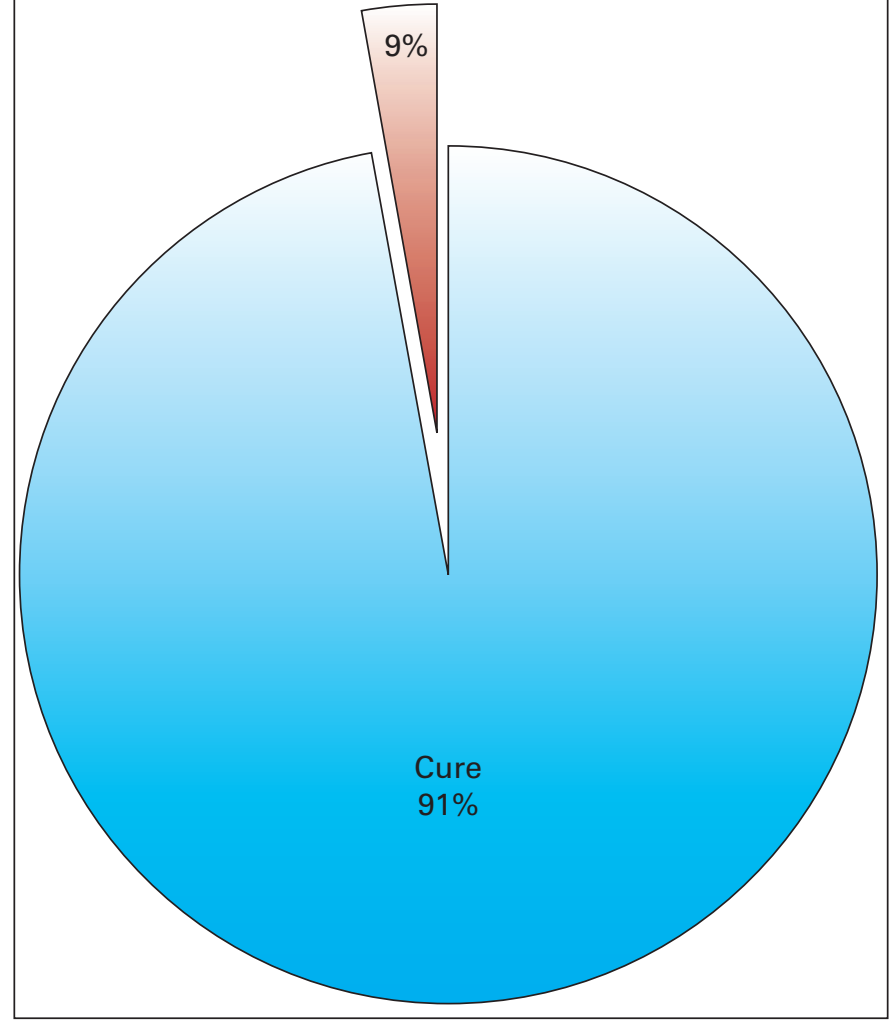

Fig. 1. Cure rate for pelvic organ prolapse.

The results of this study are in accordance with results from the largest series published so far on the use of a TVM for the treatment of POP. In 2005, Cosson and colleagues reported the results of a multicentric study involving 687 patients with 4 months of follow-up (M. Cosson, International Continence Society meeting, August 2005). The authors of that study were part of the TVM group, which developed the technique back in $2004 .{ }^{4}$ The cure rate was $95 \%$, with organ prolapse recurrence in the range of $0 \%$ to $11 \%$, depending on the centre. Vaginal erosions occurred in $0 \%$ to $13 \%$. At the 2008 American Urological Association (AUA) meeting in Orlando, Lukban and colleagues reported a multicentric prospective trial with 168 patients using a similar mesh, the Apogee system (American Medical Systems, Minnetonka, MN) (J.C. Lukban, AUA meeting, May 2008). At 6 months, the cure rate for posterior and apical wall defects were $92 \%$ and $94 \%$, respectively. No intraoperative complication was experienced, but vaginal erosions occurred in $9 \%$ of the patients. In January 2009, Elmer and colleagues published a paper on 261 patients with a follow-up of 1 year. ${ }^{5}$ The anatomical cure rate was $79 \%$ to $86 \%$. Bladder and rectal lacerations were seen in 3\% and postoperative vaginal erosions in $11 \%$. In the same month, Feiner and colleagues published a review of 8 studies and 1295 patients in which the Prolift system was used to treat apical prolapse. ${ }^{6}$ With a mean follow-up of 30 weeks, the 


\begin{tabular}{ll} 
Table 4. Complications & \\
\hline Perioperative, no. (\%) & $1(2 \%)$ \\
- Prolonged bleeding & $1(2 \%)$ \\
- Rectal laceration & 0 \\
- Bladder laceration & \\
\hline Postoperative, no. (\%) & \\
Short term & $10(18 \%)$ \\
- Urinary retention & $2(4 \%)$ \\
- Prolonged postoperative pain & $1(2 \%)$ \\
- Febrile morbidity & $5(9 \%)$ \\
Long term & $3(6 \%)$ \\
- Organ prolapse recurrence & 0 \\
- De novo urinary incontinence & \\
- Vaginal erosion &
\end{tabular}

mean objective success rate was $87 \%$ (range 75 to 94) and the mean complication rate was $16 \%$. Vaginal erosions occurred in $7 \%$.

Looking back on the results of this present study and a review of literature, the Prolift system showed a high short and mid-term cure rate, as well as a satisfactory complication profile. Therefore, it appears to be a safe and effective alternative to conventional surgeries for the treatment of recurrent or high-grade multiple compartment POP.

The limitations of this study are the retrospective method and the single-surgeon single-centre experience. Also, a high number of patients were lost in follow-up. However, it is worth noting that they did not go to their follow-up visit because they reported that they were all cured.

The strengths of this study are the relatively high number of patients for 1 surgeon and the long follow-up of 21 months compared to similar studies. In fact, we did not find a single report in which the follow-up time was so extensive.

\section{Condusion}

Considering the results of this study and a review of literature, the Prolift system appears to be a relatively safe and effective alternative to conventional surgeries for the treatment of recurrent or high-grade multiple compartment POP, because of a high mid-term cure rate and a satisfactory complication profile. However, long-term follow-up is still needed to confirm these results.

Centre Hospitalier Universitaire de Sherbrooke (CHUS), Université de Sherbrooke, Sherbrooke, QC

Competing interests: None declared.

This paper has been peer-reviewed.

\section{References}

1. Julian TM. The efficacy of Marlex mesh in the repair of severe, recurent vaginal prolapse of the anterior midvaginal wall. Am J Obstet Gynecol 1996; 175:1472-5.

2. Morley GW, DeLancey JOL. Sacrospinous ligament fixation for eversion of the vagina. Am J Obstet Gynecol 1988; 158:872-81.

3. Sze EHM, Micklos JR, Partoll L, et al. Sacro-spinous ligament fixation with transvaginal needle suspension for advenced pelvic organ prolapse and stress incontinence. Obstet Gynecol 1997;89:94-6.

4. Debodinance P, Berrocal J, Clavé $\mathrm{H}$, et al. Évolution des idées sur le traitement chirurgical des prolapsus génitaux: naissance de la technique TVM. J Gynecol Obstet Biol Reprod 2004:33:577-88.

5. Elmér C, Altman D, Engh ME, et al. Trocar-guided transvaginal mesh repair of pelvic organ prolapse. Obstet Gynecol 2009;113:117-26.

6. Feiner B, Jelovsek JE, Maher C. Efficacy and safety of transvaginal mesh kits in the treatment of prolapse of the vaginal apex: a systematic review. BJOG 2009;116:15-24.

Correspondence: Dr. Louis-Olivier Gagnon, Centre Hospitalier Universitaire de Sherbrooke (CHUS), Université de Sherbrooke, 3001, 12e ave. Nord, Sherbrooke, QC JIH 5N4; louis.olivier.gagnon@gmail.com 